\title{
DETERMINATION OF NORMAL PORTAL VEIN SIZE AND PEAK SYSTOLIC VELOCITY IN A TERTIARY CARE CENTRE IN NORTH INDIA
}

\author{
Harshita Pant ${ }^{1}$, Snehanshu Shukla ${ }^{2}$
}

${ }_{1}^{1}$ Associate Professor, Department of Radio-diagnosis, Mayo Institute of Medical Sciences, Barabanki, Uttar Pradesh, India. ${ }^{2}$ Associate Professor, Department of Microbiology, Mayo Institute of Medical Sciences, Barabanki, Uttar Pradesh, India.

\begin{abstract}
BACKGROUND
ABSTRACT

Portal vein normal waveform shows gentle undulation with flow towards the liver i.e. hepatopetal flow. In portal hypertension, with progression of disease, as sinusoidal pressure increases, the portal venous flow reduces (Slow flow) which may even stop (No flow) or flow away from liver i.e. hepatofugal flow (Reverse flow).[1,2] Various studies revealed that, the portal vein diameter (PVD) changes with the age and gender distribution. Thus this study aims to establish the normal value of portal vein diameter and PSV in north Indian population in region of Barabanki.
\end{abstract}

\section{MATERIALS AND METHODS}

A total of 108 healthy individuals with age ranging from 20 to 60 years attending Radiodiagnosis department at Mayo Institute Of Medical Sciences, Gadia, Barabanki, Uttar Pradesh, were chosen for the study. Transabdominal ultrasound was done to measure the diameter of the main portal vein with average of three measurements.

\section{RESULTS}

In present study, the portal vein diameter in males and females was $9.17 \pm 2.33 \mathrm{~mm}$ and $8.95 \pm 1.90$ mm respectively with peak systolic velocity ranging from 13 to $15 \mathrm{cms} /$ second.

\section{CONCLUSION}

In our study, portal vein diameter in adult population of 20 to 60 yrs., age group among males and females was found to be $9.17 \pm$ $2.33 \mathrm{~mm}$ and $8.95 \pm 1.90 \mathrm{~mm}$ respectively with peak systolic velocity ranging from 13 to $15 \mathrm{cms} /$ second. These parameters may be assumed as reference values in the local population of Barabanki set in northern Indian region.

\section{KEY WORDS}

Portal Vein, Portal Vein Diameter, Portal Vein Peak Systolic Velocity, Ultrasound.

HOW TO CITE THIS ARTICLE: Pant H, Shukla S. Determination of normal portal vein size and peak systolic velocity in a tertiary care centre in North India. J. Evolution Med. Dent. Sci. 2019;8(04):270-272, DOI: 10.14260/jemds/2019/58

\section{BACKGROUND}

The portal vein (PV) is a unique vein that drains blood from the capillaries of the intestinal walls and spleen to the capillaries of the hepatic sinusoids. It carries $80 \%$ of venous blood from intestine and spleen to the liver to supply up to the one half of the oxygen requirements of the hepatocytes.[3] Various studies revealed that, the portal vein diameter (PVD) changes with the age and gender distribution. ${ }^{[4,5]}$ The upper limit of portal vein diameter was found to be $13 \mathrm{~mm} .{ }^{[6]}$ Portal hypertension is the most common complication and also one of the important cause of death in chronic liver diseases.[7] Conventional angiography, computed tomography angiography and magnetic resonance angiography can be used to evaluate PV changes in CLD patients. However, ultrasound scan is preferred because it is a safe, non-invasive, cheap and readily available diagnostic tool for evaluating these patients. It is also important in monitoring of progression of the disease.[8]

'Financial or Other Competing Interest': None.

Submission 24-11-2018, Peer Review 15-01-2019,

Acceptance 22-01-2019, Published 28-01-2019.

Corresponding Author:

Dr. Snehanshu Shukla,

Plot No. 1, Basant Vihar Colony,

Behind St. Mary Int. College,

Sector-14, Indira Nagar, Lucknow,

Uttar Pradesh, India.

E-mail: shuklasnehanshu@gmail.com

DOI: $10.14260 /$ jemds $/ 2019 / 58$
Physiological flow pattern in PV has been described as continuous hepatopetal with feeble pulsatility in rhythm with cardiac and respiratory variation.[9] The normal waveform shows gentle undulation with flow towards the liver i.e. hepatopetal flow. In portal hypertension, with progression of disease, as sinusoidal pressure increases, the portal venous flow reduces (Slow flow) which may even stop (No flow) or flow away from liver i.e. hepatofugal flow (Reverse flow).[1,2] Breathing plays an important role in the variations of morphological and functional vascular parameters by modifying intra-abdominal pressure; the inspiration process increases intra-abdominal pressure, thus emptying the abdominal veins and increasing the vein-flow towards the heart. In case of the portal venous system, the venous return presents a number of particularities: the increase in the abdominal pressure during inspiration is also accompanied by a compression of the liver by the right hemidiaphragm; in conditions of a normal liver, without fibrotic changes, we will have an increased venous return from the spleno-mesenteric territory and at the same time an increase in resistance of the hepatic veins. These elements will determine an increased intravascular hydrostatic pressure leading to increased vessel dimensions: portal vein, splenic vein (SV), and superior mesenteric vein (SMV). The variation induced by respiration in portal blood flow is less in cirrhotics.[10]

The most important symptoms of liver cirrhosis, haemorrhage from oesophageal varices and ascites are due to circulatory alterations at the portal venous system. It is important to get information about portal venous system 
with the aim of discovering portal hypertension in patients with asymptomatic chronic disease.[11] Hence comes the role of portal vein assessment. This study aims to establish the normal value of portal vein diameter, PSV in north Indian population in region of Barabanki.

\section{MATERIALS \& METHODS}

This cross-sectional study was conducted in the Department of Radiodiagnosis, Mayo Institute Medical Sciences, Gadia, Barabanki, among 108 healthy individuals. Patients (50 males and 58 females), age ranged from 20 to 60 years who attended Radiodiagnosis department for conditions other than portal hypertension or any other diseases not related to portal vein directly or indirectly, diseases of liver, spleen or cardiac, malaria. Other exclusion criteria were any abdominal surgery, pregnant lady, splenomegaly, ascites, body swelling, subjects on hepatotoxic drugs such as antituberculous and antiretroviral drugs. Formal permissions from the Institutional Ethics Committee, MIMS, and written informed consent from the concerned individuals were taken. Transabdominal ultrasound was done by Siemens Acuson X 300 with $3.5 \mathrm{MHz}$ sector curvilinear and 7.5-10 MHz linear transducer probe. Study variables were: gender, age and portal vein diameter during quiet resting state breathing. The individuals were divided among four groups according to the age. Group I - 20 to 30 years, Group II - 31-40 years, Group III -41 to 50 years, Group IV- 51 - 60 years. The individuals underwent ultrasonography after overnight fasting to avoid variability in size of post meal increase in size of portal vein. With an elaborate history of present \& previous history of illness, history of alcohol consumption, menstrual history in females mainly to exclude pregnancy, a physical examination was done. The abdomen was scanned by ultrasound to check sonographic exclusion criteria, lying in supine position in relaxed conditions and in quite respiration. The portal vein was evaluated parallel to its course from splenomesenteric confluence to porta hepatis, and its bifurcation into right and left portal vein. The maximum diameter of the main portal vein between splenomesenteric confluence to division of portal vein into right and left branch was taken into consideration. Image was zoomed for better accuracy of cursor placement. The central portion of the two cursors was fixed in the inner wall of the portal vein. The wall of the portal vein was excluded from measurements.

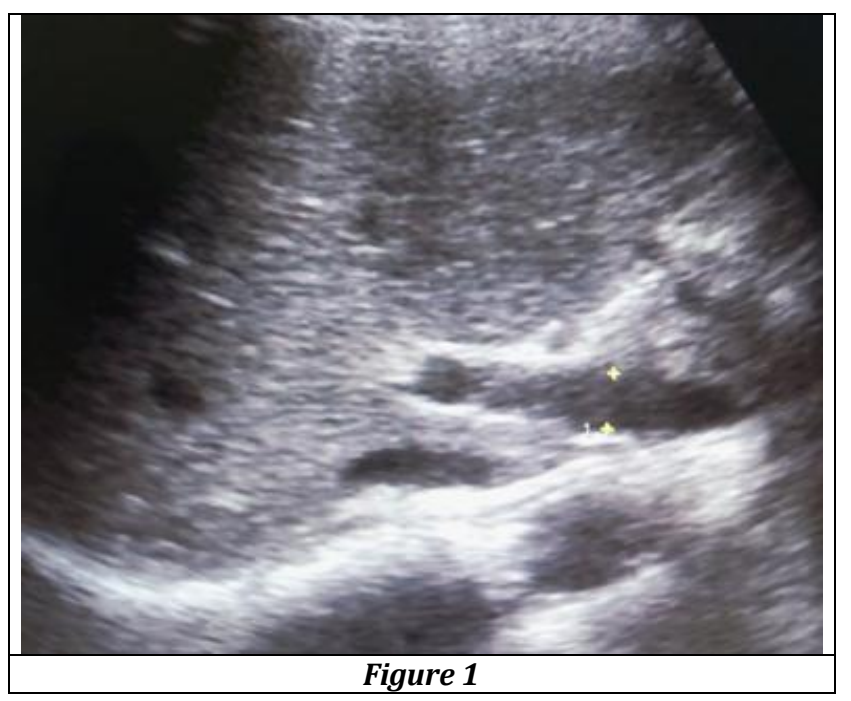

Average of three times measurements per patient was taken into account. PSV was measured with sample volume cursor at the centre of the portal vein lumen, midway between the splenomesenteric confluence and portal vein division into left and right hepatic branches. Sample volume size was taken from $2 / 3$ rd of vessel diameter.

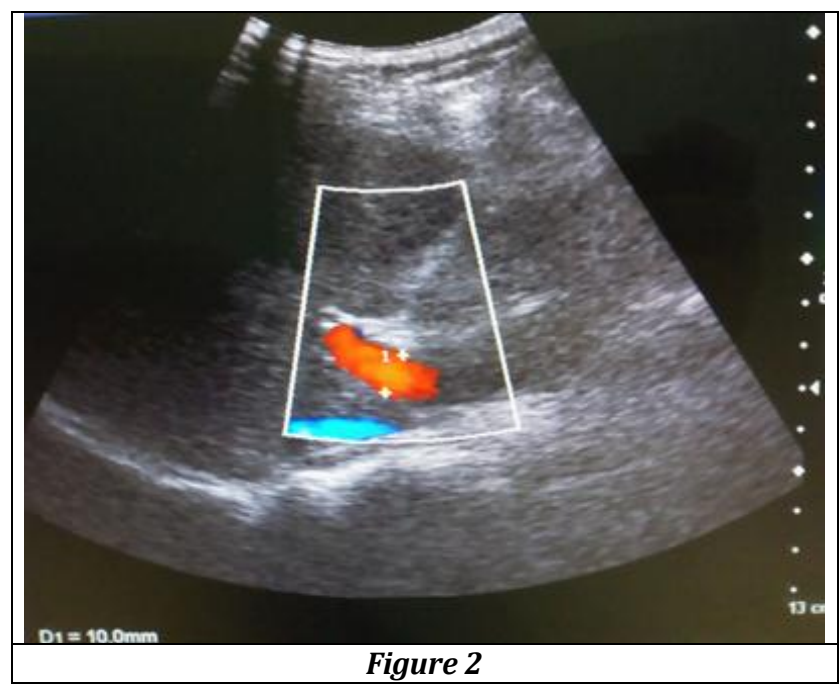

The angle between the longitudinal axis of portal vein and Doppler beam was maintained at 30-60 degrees. The mean of three consecutive spectral wave manual tracings was taken for calculation of the indices. Portal vein PSV was taken as the highest value of the sinusoidal waveform. All the individual records were entered in the master chart with full confidentiality.

\section{RESULTS}

The present study was conducted among 108 healthy individuals. The participants were divided among five groups according to their age as mentioned.

\begin{tabular}{|c|c|c|c|c|}
\hline & I & II & III & IV \\
\hline Age & $20-30$ & $31-40$ & $41-50$ & $51-60$ \\
\hline Male & 10 & 11 & 10 & 14 \\
\hline Female & 14 & 21 & 10 & 18 \\
\hline Total & $\mathbf{2 4}$ & $\mathbf{3 2}$ & $\mathbf{2 0}$ & $\mathbf{3 2}$ \\
\hline \multicolumn{5}{|c|}{ Table 1. Age Wise Groups with Constituting Gender } \\
Numbers in Each \\
\hline
\end{tabular}

\begin{tabular}{|c|c|c|c|c|c|}
\hline & I (MPD) & II (MPD) & III (MPD) & IV (MPD) & Mean \\
\hline Age & $20-30$ & $31-40$ & $41-50$ & $51-60$ & \\
\hline \multirow{2}{*}{ Male } & 9.1 & 9.14 & 9.2 & 9.25 & 9.17 \\
& $( \pm 2.1)$ & $( \pm 2.3)$ & $( \pm 2.3)$ & $( \pm 2.5)$ & $( \pm 2.3)$ \\
\hline \multirow{2}{*}{ Female } & 8.8 & 8.9 & 9.0 & 9.1 & 8.95 \\
& $( \pm 1.7)$ & $( \pm 1.9)$ & $( \pm 1.9)$ & $( \pm 2.1)$ & $( \pm 1.9)$ \\
\hline Table 2. Mean Portal Vein Diameter (MPD) According to \\
Age in Males and Females \\
\hline
\end{tabular}

\section{DISCUSSION}

A cross sectional grey scale ultrasound assessment of portal vein in Ethiopian population was done, age of the subjects varied from 5 to 85 years. The mean diameter of portal vein was calculated as $10.0 \pm 1.8 \mathrm{~cm} .{ }^{[9]}$ The results concluded that gender did not have any effect on the diameter of portal vein but with increasing age the diameter also increased. Subsequently, the same results also reported in a Nigerian population establishing the mean portal vein diameter as 
$11.45 \pm 1.45 \mathrm{~mm}$ and also concluding that the diameter varies with age but not with gender.[12] A Doppler ultrasonic study which is a more advanced and accurate imaging technique was conducted in Iran on 37 healthy subjects. The age varied from 20-40 years and the mean portal vein diameter was calculated as $9.36 \pm 1.65 \mathrm{~mm} .[13]$

In current study, the PVD diameters in males and females were $9.17 \pm 2.33 \mathrm{~mm}$ and $8.95 \pm 1.90 \mathrm{~mm}$ respectively. They ranged from 7.50 to $13 \mathrm{~mm}$ and 7.10 to $12.2 \mathrm{~mm}$ in males and females respectively. The mean diameter showed an increasing trend with age. Mean diameter was higher in males than in females.

A wide variation of mean portal vein diameter was established by previous studies ranging from 7.9- to 11.7$\mathrm{mm}$. [7-10] The wide variation is possibly due to variation in the study population, geography, ethnicity and measurement techniques.

Diameters of splenic and superior mesenteric veins were varied, increased during inspiration and decreased during expiration, significantly in all controls. Kurol and Forsberg opined that there was no established limits of respiratory variation in normal individuals.[14] However, a respiratory variation of less than 30 per cent in normal individuals should be considered pathological.

\section{CONCLUSION}

Portal vein diameter in local population may provide a reference value for assessing variation of size and peak systolic velocity for clinical practice. In our study, portal vein diameter in adult population of 20 to 60 yrs. age group among males and females was found to be $9.17 \pm 2.3 \mathrm{~mm}$ and $8.95 \pm 1.90 \mathrm{~mm}$ respectively with peak systolic velocity ranging from 13 to $15 \mathrm{cms} /$ second. The mean diameter showed an increasing trend with age. Mean diameter was higher in males than in females.

These parameters may be assumed as reference values in the local population of Barabanki set in northern Indian region.

\section{REFERENCES}

[1] Wilson SR, Withers CE. The liver. In: Rumack CM, Wilson SR, Charboneau JW, et al. eds. Diagnostic ultrasound. Vol. 1. 4th edn. Philadelphia: Mosby Inc., 2011: p. 78-145.

[2] McNaughton DA, Abu-Yousef MM. Doppler US of the liver made simple. Radiographics 2011;31(1):161-88.
[3] Wilson SR, Withers CE. The liver. In: Rumack CM, Wilson SR, Charboneau JW, eds. Diagnostic ultrasound. Part II. Vol. 1. $3^{\text {rd }}$ edn. St. Louis: Mosby, Elsevier 2005: p. 75-145.

[4] Anakwue AC, Anakwue RC, Ugwu AC, et al. Sonographic evaluation of normal portal vein diameter in Nigerians. European J Sci Res 2009;36(1):114-7.

[5] Hawaz Y, Admassie D, Kebede T. Ultrasound assessment of normal portal vein diameter in Ethiopians done at Tikur Anbessa Specialized Hospital. East \& Cent Afr J Surg 2012;17(1):90-3.

[6] Cosgrove DO. Liver anatomy. In: Cosgrove D, Meire H, Dewbury K, et al. eds. Clinical ultrasound a comprehensive text - abdominal and general ultrasound. Vol. 1. Edinburgh: Churchill Livingstone 1994: p. 227-42.

[7] Bosch J, Garcia-Pagan JC. Complications of cirrhosis. I. Portal hypertension. J Hepatol 2000;32(Suppl 1):14156.

[8] Abigail T, Timothy H. Peripheral vascular ultrasound: How, When and Why? 2nd edn. Edinburgh: Elsevier/ Churchill Livingstone 2005: p. 10-4.

[9] Zwiebel WJ, Fruechte D. Basics of abdominal and pelvic duplex: instrumentation, anatomy and vascular Doppler signatures. Semin Ultrasound CT MR 1992;13(1):3-21.

[10] Lazăr M, Ion DA. Physiological variations of the portal flow parameters and their clinical relevance. J Contemp Clin Pract 2015;1(1):7-14.

[11] Bolonndi L, Gandolfi L, Arienti V, et al. Ultrasonography in the diagnosis of portal hypertension: diminished response of portal vessels to respiration. Radiology 1982;142(1):167-72.

[12] Anakwue AC, Anakwue RC, Ugwu AC, et al. Sonographic evaluation of normal portal vein diameter in Nigerians. Euro J Sci Res 2009;36(1):1147.

[13] Yazdi HR, Sotoudeh H. Assessment of normal Doppler parameters of portal vein and hepatic artery in 37 healthy Iranian volunteers. Iran J Radiol 2006;3:213-6.

[14] Kurol M, Forsberg L. Ultrasonographic investigation of respiratory influence on diameters of portal vessels in normal subjects. Acta Radiologica Diagnosis (Stockh) 1986;27(6):675-80. 